\title{
OS IDOSOS E O USO DE PRÓTESES AUDITIVAS: IDENTIFICANDO OS REPERTÓRIOS INTERPRETATIVOS QUE JUSTIFICAM ESSA DECISÃO
}

\author{
Luciana M. Ribeiro e Emerson F. Rasera \\ Universidade Federal de Uberlândia, Uberlândia, Brasil
}

\begin{abstract}
RESUMO: O objetivo deste estudo foi descrever os repertórios interpretativos utilizados por idosos deficientes auditivos sobre a decisão de usar próteses auditivas. Foram entrevistados cinco idosos, de ambos os sexos, deficientes auditivos e usuários de próteses auditivas. Os dados foram analisados segundo as propostas de análise do discurso influenciadas pela perspectiva construcionista social. Como resultados, observamos que os usuários de prótese justificaram a sua decisão através da utilização de cinco repertórios: (1) o incômodo da repetição; (2) em busca da prevenção e autocuidado; (3) aproveitando um recurso tecnológico benéfico; (4) os benefícios superam as limitações e (5) a virtude da resignação. Buscando combater as fragilidades de cada um desses repertórios, os mesmos foram utilizados de maneira combinada. Concluímos, então, que, ao utilizar tais repertórios, os entrevistados procuraram legitimar sua decisão de usar a prótese auditiva, mostrando que a mesma foi tomada de maneira criteriosa e que, portanto, deve ser respeitada.
\end{abstract}

PALAVRAS-CHAVE: idosos; auxiliares de audição; repertórios interpretativos; construcionismo social.

\section{THE ELDERLY AND THE USE OF HEARING AIDS: IDENTIFYING THE INTERPRETATIVE REPERTORIES THAT JUSTIFY THIS DECISION}

ABSTRACT: The aim of this study was to describe the interpretative repertoires used by hearing impaired elders in choosing to use hearing aids. Five hearing impaired elders, of both sexes, who used hearing aids, were interviewed. Data analysis was performed according to Discourse Analysis by Constructionist Approach. As results, we observed that the hearing aid users justified their decision using five repertoires: (1) The disturb of repetition; (2) Seeking prevention and self-care; (3) Taking advantage of a beneficial technological resource(4) The benefits surpass the limitations (5) The virtue of resignation. Seeking to combat the fragilities of each of these repertoires, they were used in a combined manner. We concluded that, when such repertoires were used, the interviewers sought to legitimize their decision to use hearing aids, demonstrating that this decision was taken in a critical manner and so must be respected.

KEY WORDS: elderly; hearing aids; interpretative repertories; social constructionism

\section{Introdução}

O envelhecimento mundial é um fenômeno que tem sido muito discutido nas últimas décadas. De acordo com os dados do Instituto Brasileiro de Geografia e Estatística (IBGE, 2002), o Brasil está passando por uma fase de transição demográfica, com o crescimento da população idosa. Os cidadãos brasileiros com 60 anos ou mais já somam quase 15 milhões de habitantes. As estatísticas prevêem que em 2020 a população idosa poderá exceder 30 milhões de pessoas, chegando a representar quase $13 \%$ da população do país. Os resultados da Pesquisa Nacional por Amostra de Domicílios, Pnad, (IBGE, 2007), apontam que a tendência de envelhecimento populacional, já observada em anos anteriores, persiste, o que é comprovado pelo aumento do número de idosos na população total residente. Com essa realidade, tal população passa a receber maior atenção, tornando evidentes suas necessidades e os problemas decorrentes do envelhecimento (Bacelar, 2002; Papaléo Netto \& Ponte, 1997).

Atualmente, com o entendimento de que a velhice não significa necessariamente doença, e sendo o idoso capaz de mudanças, o significado de envelhecimento bemsucedido passa a ter maior importância, considerando o grande número de pessoas que espera gozar de uma longa velhice (Freire, 2000).

Apesar de todo esse contexto de velhice bem-sucedida, não é verdade que o envelhecimento não aconteça, ou que não ocorram modificações neste período. Sabe-se que essa etapa da vida pode vir acompanhada de perdas psicossociais, além de consequiências biológicas, dentre as quais podemos citar: alterações na saúde geral, problemas de destreza manual, a deficiência visual e a deficiência auditiva (Rigo \& Teixeira, 2005; Russo,Almeida, \& Freire, 2003). 
Segundo Hull (1999), um dos mais frustrantes déficits sensoriais que acompanham o processo de envelhecimento é a deterioração da função auditiva, conhecida como presbiacusia, a qual pode ser definida como uma desordem auditiva multidimensional que afeta cerca de $40 \%$ de todas as pessoas com idade acima de 65 anos. Esta desordem é caracterizada pela redução da sensibilidade auditiva e da compreensão da fala em ambientes ruidosos, lentidão do processamento de informações acústicas e dificuldade na localização de fontes sonoras. Como resultado, as pessoas com essa desordem têm dificuldades em situações de conversação, ouvir música, orientar-se com sons de alarme e participar de atividades sociais (Gates \& Mills, 2005).

A queixa básica apresentada pelos indivíduos com presbiacusia é a de que "Escuto, mas não entendo." Isso acontece devido ao fato da perda auditiva em altas frequiências dificultar a percepção das consoantes, principalmente em ambientes com ruído (Russo, Almeida, \& Freire, 2003). Além das dificuldades comunicativas apresentadas, observa-se ainda que a perda auditiva traz consequiências psicossociais como isolamento, depressão, frustração, irritabilidade, sentimento de solidão, entre outros (TeschRömer, 1997).

De acordo com a literatura científica (Russo, Almeida, \& Freire, 2003; Veras \& Mattos, 2007), para que os problemas de comunicação do deficiente auditivo idoso possam ser amenizados, é necessário um programa de reabilitação audiológica, incluindo em tal programa a adaptação de próteses auditivas, popularmente conhecidas como aparelhos auditivos.

Graças ao avanço tecnológico obtido nas duas últimas décadas, pode-se dizer que, atualmente, a maioria dos indivíduos portadores de perda auditiva irá obter benefícios com o uso desses equipamentos (Almeida, 2004; Assayag \& Russo, 2006; Buzo, Ubrig, \& Novaes, 2004; Silman, Iório, Mizhahi, \& Parra, 2004). Apesar disso, ainda é grande o número de idosos com presbiacusia que optam por não utilizar as próteses auditivas. As pesquisas mostram que apenas cerca de $20 \%$ dos indivíduos idosos com perda de audição significativa adquirem as próteses (Kochkin, 2003).

Suspeita-se que muitos aspectos, como, por exemplo, estigma (Erler \& Garstecki, 2002), preconceito (Fialho, 2001), negação da surdez (Iervolino, Castiglioni, \& Almeida, 2003) e associação da perda de audição com a velhice (Costa, 2006), possam contribuir na decisão sobre o uso das próteses. Entretanto, não se sabe de que forma tais sentidos são produzidos e como podem influenciar nesta decisão.

Esta constatação nos levou a questionar sobre o que dizem os idosos que decidiram usar a prótese auditiva sobre temas como ouvir, surdez, próteses auditivas e velhice, e se os sentidos por eles produzidos em relação a esses temas, de alguma forma, os auxiliaram a tomar a decisão de usar a prótese auditiva. Passamos a querer compreender principalmente como essas pessoas justifi- cam a decisão de usá-las, já que são uma minoria, quando o que se esperava é que fossem a maioria.

Analisando a questão com um olhar construcionista

Ao realizar o levantamento da bibliografia existente a respeito de adaptação de próteses auditivas em idosos, constatamos que vários estudos já foram realizados na tentativa de se compreender os aspectos psicossociais que permeiam essa questão (Hull, 1999; Russo, 2004; Weinstein \& Ventry, 1982). Contudo, a grande maioria desses estudos foi realizada apenas de forma quantitativa, através da aplicação de escalas e questionários fechados. Por este motivo, entendemos que se fazia necessária a realização de pesquisas qualitativas que complementassem o entendimento trazido por esses estudos, já que, enquanto estes convidam o pesquisado a se inserir na lógica do pesquisador, a pesquisa qualitativa propicia a construção de dados sobre as particularidades dos indivíduos, ou seja, o pesquisador é que passa a ser convidado a entrar na lógica do pesquisado.

Uma das atuais vertentes epistemológicas que sustentam a prática da pesquisa qualitativa para a construção do conhecimento é o Construcionismo Social, que tem desenvolvido uma nova concepção teórica baseada em uma visão não-empiricista do funcionamento da ciência e suas formas de investigação, redimensionando, dessa forma, os pressupostos sobre a produção do conhecimento. Nesta abordagem, os processos relacionais, que ocorrem por meio da linguagem, passam a ocupar posição de destaque (Rasera \& Japur, 2001).

Um dos principais difusores dessa vertenteé Kenneth Gergen $(1985,1997)$, que afirma que "a investigação sócio-construcionista preocupa-se sobretudo com a explicação dos processos por meio dos quais as pessoas descrevem, explicam ou dão conta do mundo (incluindo a si mesmos) em que vivem" (Gergen, 1985, p. 266).

Um dos aspectos que o construcionismo social se propõe a investigar são as produções de sentidos no cotidiano, ou seja, a forma com que as pessoas, em suas relações sociais, constroem os termos com os quais irão significar as situações e fenômenos ao seu redor. Essa produção de sentidos é tida como um fenômeno sociolingüístico, uma vez que o foco se encontra na linguagem em uso e busca compreender tanto as práticas discursivas que acontecem no dia-a-dia (narrativas, argumentações, conversas etc.) como os repertórios utilizados em tais produções discursivas (Spink \& Medrado, 2004).

Potter e Wetherell (1996), assim como Spink e Medrado(2004), utilizam-se do termo repertórios interpretativos para designar o que seriam as unidades de construção das práticas discursivas, ou seja, o conjunto de termos que demarcam as possibilidades de produção de sentidos e posicionamento nas relações sociais cotidianas, tendo por parâmetro o contexto em que tais práticas são produzidas. Segundo esses autores, é por meio dos repertórios 
interpretativos que podemos entender tanto a estabilidade quanto a dinâmica e a variabilidade das produções lingüísticas humanas, ou seja, a variabilidade frequientemente encontrada nas comunicações do dia-a-dia, quando repertórios próprios de diferentes discursos são combinados de maneiras pouco usuais, obedecendo a uma linha de argumentação, mas gerando também algumas contradições. Para esses autores, os repertórios interpretativos são basicamente um registro dos termos e metáforas utilizadas para caracterizar e avaliar ações e eventos.

Diante disso, pensamos que a possibilidade de identificar os repertórios interpretativos sobre o uso de próteses auditivas nos auxiliará a entender melhor tais processos de produção de sentidos e, conseqüentemente, nos servirá de guia para o aconselhamento e atendimento dessa população, já que poderemos compreender de forma mais ampla quais os sentidos que permeiam a decisão do uso da prótese auditiva e de que forma isso acontece.

Sendo assim, o objetivo deste estudo é descrever os repertórios interpretativos utilizados por idosos portadores de deficiência auditiva, em situação de entrevista, sobre a decisão de usar próteses auditivas.

\section{Método}

Participantes: Foram entrevistados cinco idosos (60 anos ou mais), de ambos os sexos, sendo dois homens e três mulheres, com média de idade de 77 anos, portadores de deficiência auditiva neurossensorial bilateral adquirida, com configuração auditiva característica de presbiacusia e usuários de prótese auditiva.Todos eles receberam indicação do médico otorrinolaringologista para teste com próteses auditivas e buscaram atendimento em uma clínica privada na qual a autora principal deste estudo trabalha como fonoaudióloga clínica, e que, portanto, foi quem realizou o trabalho de seleção, teste e adaptação de próteses auditivas nesses indivíduos.

A escolha dos participantes se deu de forma aleatória, por meio de sorteio dos nomes contidos no cadastro de pacientes dos últimos dois anos. Os indivíduos foram convidados a participar da pesquisa por meio de ligações telefônicas, momento este em que a pesquisadora explicava sobre o que tratava a entrevista, seus objetivos e a forma como seria realizada. Dos indivíduos contactados, apenas uma senhora se recusou a participar, alegando vergonha em ter seus relatos gravados em áudio e "não saber falar bem."

Procedimentos para a construção e análise dos dados: Os dados foram construídos através da realização de entrevistas semi-estruturadas, as quais foram feitas pela pesquisadora e gravadas em fita cassete, utilizando-se, para esse fim, um gravador da marca Aiwa, modelo HS-JS199. Cada entrevista teve uma duração média de 60 minutos. O roteiro de entrevista foi composto por quatro perguntas principais, em que a pesquisadora perguntava aos participantes o que vinha em suas cabeças quando ela dizia a palavras "ouvir", "surdez", "aparelho auditivo" e "idoso" seguidas de perguntas de apoio. É importante considerar que o roteiro de entrevista serviu apenas como um instrumento norteador. Assim, na medida em que o diálogo ia se desenvolvendo, as perguntas de apoio eram realizadas e outras perguntas eram formuladas, buscando atender o objetivo principal da entrevista, qual seja, compreender os sentidos construídos pelos participantes para os temas abordados.

Ressalta-se que a idéia inicial era entrevistar todos os participantes em suas residências, pois buscávamos um contexto mais familiar aos entrevistados, menos marcado pelas rotinas clínicas e fonoaudiológicas de um local de cuidado em saúde, e mais aberto e sensível às peculiaridades da vida de cada entrevistado. Entretanto, alguns indivíduos, principalmente homens, alegaram se sentir mais à vontade indo até a clínica do que recebendo a pesquisadora em suas casas. Como este era o objetivo principal de entrevistá-los em suas casas (fazê-los se sentirem mais à vontade para relatarem o que quisessem), consentimos realizar a entrevista no local onde o participante se sentisse melhor.

Antes de iniciar as entrevistas, os participantes leram e assinaram o Termo de Consentimento Livre e Informado, o qual continha, inicialmente, informações sobre a pesquisa e seus objetivos. É importante destacar que, durante a apresentação de trechos das entrevistas neste trabalho, foram utilizados nomes fictícios com o objetivo de resguardar a identidade dos participantes.

Ressalta-se, ainda, que o projeto aqui apresentado foi aprovado pelo Comitê de Ética em Pesquisa da Universidade Federal de Uberlândia sob o parecer n ${ }^{\circ}$ 187/06.

A análise dos dados foi realizada segundo as propostas de análise do discurso influenciadas pela perspectiva construcionista social (Potter, 1996; Rasera \& Japur, 2007, Spink, 2004). Assim, os passos da análise consistiram de: (a) transcrição de todas as entrevistas realizadas; (b) leitura flutuante, curiosa e reflexiva das transcrições visando à construção de categorias que nortearam a análise de todo o material; (c) identificação dos repertórios interpretativos, os quais foram construídos através do reconhecimento e agrupamento das imagens, adjetivos, expressões e figuras de linguagem produzidas pelos entrevistados para justificar a decisão de usar as próteses auditivas e (d) análise dos repertórios identificados, buscando compreender os posicionamentos assumidos pelos participantes durante as entrevistas e as implicações morais associadas à utilização destes repertórios.

\section{Resultados e Discussão}

Buscando facilitar a percepção do uso dos repertórios interpretativos de maneira individual e combinada, 
dividimos a análise em duas partes principais, as quais denominamos de "Usar prótese auditiva: explicando essa decisão" e "Uso combinado de repertórios".

Na primeira parte, procuramos descrever e analisar, de forma separada, os repertórios interpretativos por nós identificados e que foram utilizados pelos entrevistados para justificar a decisão de usar as próteses auditivas. Na segunda parte, poderemos visualizar o seu uso de maneira combinada, auxiliando-nos a perceber que os mesmos são utilizados buscando atender às necessidades conversacionais de cada momento, demonstrando, então, o caráter contextual e situacional do seu uso. Buscando exemplificar o uso desses repertórios em cada uma das situações, selecionamos alguns trechos de entrevistas que possibilitassem a visualização do que procuramos descrever ao longo de cada análise.

\section{1) Usar prótese auditiva: explicando essa decisão}

A análise das entrevistas transcritas resultou na identificação de cinco repertórios interpretativos dominantes que justificam a decisão dos entrevistados de usar próteses auditivas, apresentados a seguir:

\section{A) $\mathrm{O}$ incômodo da repetição}

Através do uso deste repertório, pudemos constatar que, para estes indivíduos, usuários de prótese auditiva, pedir ao interlocutor que repita o que foi dito é algo que parece causar desconforto. Expressões como "cara de bobo", "envergonhado" e "constrangido" são utilizadas por eles com a finalidade de ilustrar estas situações.

Trecho 1

L: Isso aqui a sra. já me respondeu durante a entrevista, mas eu vou perguntar de novo, tá? Por que a sra. decidiu usar o aparelho?

Z: Porque eu tava sentido necessidade de ouvir melhor, né? Porque você precisar das pessoas ficar repetindo, você não ouvir direito, né, e a gente às vezes, as pessoas em casa, a gente tá conversando assim e não tá entendendo nada. Eu não cheguei tanto assim não, né, mas às vezes a pessoa tão contando alguma coisa assim, se você num fixa mesmo a atenção, você não entende, depois che fica com cara de bobo aí e não entendeu nada .... (Zilá)

Trecho 2

L: E aí seu Sérgio, quando acontecia isso, antes de $o$ sr. estar com o aparelho, o sr. tava sentado e não entendia as pessoas. Como que o sr. fazia pra contornar a situação?

S: A gente saía, uai, não adianta tá teimando, né?

L: Saia de perto?
S: Saía, porque ficar perguntando e atrapalhando assunto dos outros a gente não vai né? A gente sente envergonhado: "Que que é que cê tá falando? Que que é, num intindi." (Sérgio)

Podemos verificar aqui que o "incômodo da repetição" está associado à relação que se tem com o outro. A preocupação maior é com a reação do interlocutor frente ao pedido de repetição. Existe um receio de incomodar o outro ou receber um julgamento desfavorável como, por exemplo, parecer uma pessoa intelectualmente desfavorecida, ou seja, "boba", por não ter compreendido o que foi dito.

Nesses casos, a dificuldade de ouvir e, conseqüentemente, compreender, parece abalar essa relação de duas formas:

1) Expondo o idoso a situações de constrangimento e embaraço social (trecho 1);

2) Atrapalhando o outro por interromper o fluxo da conversa, incomodando-o, forçando-o a repetir (trecho 2).

Assim, podemos dizer que este repertório é utilizado pelos entrevistados com a função de apresentá-los como pessoas educadas, discretas e cordiais. Além de tais qualidades, podemos dizer ainda que o uso deste repertório carrega consigo o intuito da formação de uma imagem dos entrevistados de pessoas que se importam com os outros, que não querem atrapalhar, que não pensam somente em si e, portanto, não são egoístas.

Sabemos que, mesmo utilizando as próteses auditivas, os indivíduos ainda passam por algumas situações de não entendimento, principalmente em lugares ruidosos ou quando há conversas de grupos, já que a prótese não restaura integralmente a função auditiva e, conseqüentemente, não soluciona todos os problemas de comunicação (Almeida, 2004; Iervolino, Castiglioni, \& Almeida, 2003). Nessas situações, para que haja a compreensão do que está sendo dito, ainda é necessário lançar mão de estratégias auxiliares, como pedir para repetir novamente. Isso se torna, portanto, uma fragilidade deste repertório, já que o uso das próteses não costuma sanar por completo este problema. Então, para fortalecer a assertividade da decisão de se usar a prótese auditiva, alguns entrevistados utilizam-se do repertório "Em busca da prevenção e autocuidado", como uma justificativa adicional para o uso dos aparelhos.

B) Em busca da prevenção e autocuidado

Neste repertório, identificamos trechos de conversas nos quais os entrevistados associam o uso da prótese auditiva a uma forma de prevenção de problemas futuros e de cuidado consigo mesmos. Expressões como "tenho que cuidar de mim" e "eu me gosto" são utilizadas para realçar essa idéia.

L: E antes da sra, é... descobrir que tinha perda de audição, antes de ter o aparelho, a sra. sabe se a sra. pensava alguma coisa sobre o aparelho, já ti- 
nha alguma noção? O que a sra. entendia por aparelho auditivo?

Z: Não, porque quando eu comecei a perceber que....que tava assim, não tava ouvindo bem, falei: "Uai gente, assim como a gente precisa de óculos também pode precisar do aparelho”, né? Já que tem o aparelho, né? Então eu pensei de a gente procurar né, porque...é ficar assim e, e....como eu sou uma pessoa ativa e pode piorar mais, né? Porque se eu soubesse que não fosse piorar, às vezes nem teria colocado o aparelho, né? Mas a gente sabendo que a tendência é piorar mais, aí eu falei: "não, eu tenho que cuidar de mim” (Zilá)

Podemos perceber que para os entrevistados que usam este repertório, usar a prótese auditiva significa cuidar de si. Observamos ainda que o uso do aparelho funciona quase que como um recurso preventivo. Isso fica claro quando dizem que "se soubesse que não ia piorar, às vezes nem teria colocado o aparelho" e "eu num tinha motivo [para usar o aparelho], porque conversando com você eu tô sem o aparelho". Isso mostra que, neste repertório, uma importante função do uso da prótese é tentar impedir que o problema se agrave.

Através deste repertório, as pessoas tentam passar ao outro a idéia de que são cuidadosas consigo mesmas, que se valorizam e por isso procuram prevenir problemas futuros utilizando os recursos que lhes são oferecidos. $\mathrm{O}$ uso deste repertório também ajuda a combater uma visão do indivíduo como alguém que realmente necessita do aparelho por ter uma deficiência auditiva significante. Desta maneira, ele ajuda a minimizar, na interação com o entrevistador, o possível estigma relacionado à deficiência auditiva e ao uso de prótese auditiva, já que o entrevistado se coloca como alguém que usa, mas não precisa ou usa para se prevenir de um problema futuro.

Com relação ao repertório do uso da prótese apenas com um objetivo futuro, qual seja, o da prevenção, e, portanto, sem fornecer benefícios imediatos, como melhora da audição e da compreensão, pensamos que tal justificativa, por vezes, possa causar estranheza às outras pessoas, já que estes deveriam ser os objetivos principais de quem decide usar uma prótese auditiva. Então, para combater essa possível impressão e fragilidade, os indivíduos precisam mostrar que as próteses também trazem os benefícios tidos como imediatos e principais, que é o que veremos no repertório seguinte.

C) Aproveitando um recurso tecnológico benéfico

Pôde-se perceber que alguns usuários entrevistados descrevem a prótese como um recurso tecnológico que traz benefícios para sua vida e seu dia a dia. Nesses casos, o uso da prótese é tido como algo natural, um recurso óbvio para quem possui perda auditiva e, por esse motivo, a decisão de usá-la é tomada sem maiores questionamentos. Palavras e expressões como "benefí- cio", "auxílio" e "invenção perfeita" fazem parte deste repertório.

L: E o que que o sr pensa sobre aparelho auditivo? Qual que é a visão do sr sobre aparelho auditivo? Aparelho auditivo em geral, não precisa ser só o que o sr usa, tá?

S: Eu acho o seguinte, que é um auxílio muito grande que a gente recebe hoje. Porque antigamente não tinha essas coisa. Hoje já tão tendo e cada vez. mais é... como se diz... mais é... cada vez com mais tecnologia, né? Então, quanto mais tecnologia, mais benefício traz pra pessoa que usa. Eu tô usando há pouco tempo e já to sentindo os benefícios que o aparelho nos traz.

L: E antes do sr saber, perceber que tava com essa perda de audição, o sr já conhecia alguma coisa sobre aparelho auditivo seu Samuel?

S: Não, a gente ouvia falar, mas a gente não tinha conhecimento da tecnologia, como que funcionava, isso a gente não sabia, mas já há bastante tempo que a gente já ouve falar em aparelho auditivo.

L: Mas o sr tinha uma visão de que era alguma coisa que realmente ajudava...

S: Ah, sem dúvida eu num... Porque é lógico que quem usa tem, sente o benefício que traz, né? A pessoa... isso nos auxilia naquela deficiência que a gente tem quando não usa, não tem o aparelho. Ele eu acho que é um auxiliar muito grande pra gente que... a gente já passa a compreender melhor, entender o que as pessoas... então isso tudo é um auxílio que a gente recebe do aparelho, né? (Samuel)

Neste repertório, os entrevistados parecem querer mostrar que tomaram uma decisão acertada ao decidirem adquirir e usar as próteses auditivas, já que as mesmas lhes trouxeram grandes benefícios e melhora da qualidade de vida. Para exemplificar tais benefícios, os usuários trazem relatos de situações do cotidiano em que os aparelhos se mostraram extremamente úteis e eficazes.

Através deste repertório, os entrevistados buscam se apresentar como pessoas atualizadas e inovadoras, que conhecem e fazem uso dos recursos tecnológicos disponíveis. Além disso, são pessoas flexíveis e abertas, que aceitam mudanças e se adaptam a elas.

Entretanto, observa-se que estes entrevistados, mesmo fazendo uso das próteses e percebendo seus benefícios, ainda assim possuem queixas com relação ao desempenho do aparelho em algumas situações. Então, para combater a fragilidade deste repertório, que se mostra ineficiente frente a tais situações, e para não parecerem pessoas ingênuas, utilizam também o repertório a seguir. 
D) Os benefícios superam as limitações

Com o uso deste repertório, os entrevistados demonstram que, apesar de perceberem os benefícios do uso das próteses auditivas, são conscientes de que as mesmas também apresentam limitações, mas que estas não são suficientes para que se opte por não usar os aparelhos. Sucintamente, podemos dizer que, para eles, os benefícios superam as limitações. Observamos aqui situações de reconhecimento do benefício seguidas sempre de algum comentário ressaltando a percepção de certa limitação da prótese e o desejo de que tal problema seja solucionado.

L: Tá certo. E o que que a sra pensa, D. Iara, sobre aparelho auditivo? $O$ que que aparelho auditivo é pra sra? Em geral?

I: Ah, é uma coisa que é muito boa porque a gente escuta mais. E espero que um dia vocês, ou quem trabalha nisso, vai procurar saber como que a gente vai escutar quando tem bastante gente, que isso daí faz falta. (Iara)

Como podemos perceber, as principais queixas se referem à dificuldade de compreensão em situações em que há vários interlocutores, como já havíamos comentado anteriormente. Nas entrevistas que realizou com idosos deficientes auditivos, Costa (2006) percebeu que os sentidos do uso das próteses auditivas se relacionaram ao de equipamentos que auxiliam no restabelecimento do contato com o outro, mas que não o fazem de forma integral, já que não solucionam todas as dificuldades comunicativas provenientes da deficiência auditiva, descrição que também é utilizada pelos idosos aqui entrevistados.

O uso do repertório acima tem a finalidade de posicionar os entrevistados como pessoas conscientes e conhecedoras da situação. Admitir a existência de tais limitações os afasta da imagem de pessoas ingênuas ou iludidas e os aproxima da imagem de pessoas realistas, que possuem a dimensão exata dos prós e contras de se usar um aparelho auditivo.

\section{E) A virtude da resignação}

Neste tópico, identificamos algumas falas em que os entrevistados se colocam discursivamente no lugar de alguém que "aceita as dificuldades" com resignação, e pacificamente, sem se revoltar com a situação. Diferentemente dos outros repertórios, este não se restringe ao uso do aparelho auditivo, mas diz respeito a um modo de se posicionar na vida. Contudo, a atitude de resignação parece ser vista como um agente facilitador do processo de adaptação das próteses.

L: E como é que a sra se sente quando isso acontece, D. Joana? De tá num lugar, de ter algumas pessoas falando e a sra sem saber nada?

J: Uai, eu tenho que conformar com aquilo. $O$ que que eu vou fazer, eu vou desesperar? Eu vou ficar...não. Num fico não. No começo eu ficava, mas agora não.

\section{L: Ficava o que?}

J: Ficava assim, deprimida né, achando ruim. Depois eu entendi que aquilo não era daquele jeito, eu tenho tanta coisa que eu, que não era meu que eu tô usando, né? Como bem o óculos, como bem a prótese [dentária], e tô aqui vivendo há quanto anos desse jeito. Então a mesma coisa é essa aqui [apontando para a prótese auditiva].

L: E a sra acha que a sra aceitaria [depender dos filhos]?

J: Aceita né Luciana. A gente é obrigado, a gente tem, tem que entender que tem que ser daquele jeito. Eu sou uma pessoa, eu sou uma pessoa assim, eu sou muito independente, mas eu sou uma pessoa que aceito as coisas. Quando eu vejo que precisa de aceitar, eu tenho aceitação. Graças a Deus eu entendo isso. Precisa de aceitar? Precisa. Igual esse aparelho uai! Eu sei que eu preciso dele, eu não vivo sem ele, como é que eu vou fazer? Que que dianta eu ficar revoltada com isso? Não adianta nada eu ficar revoltada com isso. Então eu tenho é que entender que eu preciso e procurar aceitar e aceitar. (Joana)

Podemos notar que os entrevistados buscam fazer reflexões que mostrem que usar a prótese não é tão complicado. Para embasar essas reflexões, argumentam que já passaram por outros processos de adaptação parecidos, e hoje estão bem, e que usar a prótese é algo menor se comparado a tantas coisas positivas que o entrevistado possui em sua vida.

Assim sendo, o repertório da virtude da resignação é usado com a finalidade de difundir a idéia de que são pessoas sábias, que conseguem compreender e aceitar as dificuldades sem se revoltar. Passam ainda a idéia de pessoas agradecidas pelos privilégios obtidos durante a vida e capazes de refletir a respeito das adversidades e superá-las pacificamente.

Observamos também que este repertório traz consigo idéias de religiosidade, que podem ser observadas através do uso freqüente de expressões como "Graças a Deus" e "Tenho muito Deus". É importante lembrar que estas são mulheres católicas e que, dentro da religião, a resignação é vista como uma grande qualidade. Assim, ser resignada as faz também cumpridoras do seu papel de cristãs.

Percebemos ainda que este foi um repertório usado preferencialmente por mulheres, o que nos faz refletir também a respeito do lugar social da mulher idosa, de 
quem se espera comportamentos de resignação e passividade (Giacomin, Uchoa, \& Lima-Costa, 2005).

É importante observar que, nas análises aqui realizadas, procuramos finalizar a apresentação de cada repertório expondo suas possíveis fragilidades e mostrando a possibilidade de combatê-las através do uso do repertório seguinte. Entendemos que essa maneira seqüencial de apresentar os repertórios poderia favorecer a compreensão e encadeamento das idéias propostas. Entretanto, é importante deixar claro que o uso de um repertório pode servir para combater a fragilidade de vários outros, e não só daquele que foi apresentado anteriormente.

De acordo com a abordagem construcionista, as pessoas usam os repertórios disponíveis para desempenhar funções sociais em um contexto particular. Assim, diferentes repertórios podem ser desenvolvidos com o intuito de atender a diferentes funções da fala, as quais se modificam dependendo do contexto de conversação. As pessoas utilizam maneiras diversas para falar sobre um aspecto particular de seu universo, dependo da mudança de propósito de sua fala, o que varia de situação para situação. O resultado dessas mudanças de intenção se reflete nas variações da fala, as quais, muitas vezes, são interpretadas como contraditórias, inconsistentes e incoerentes (Potter \& Wetherell, 1995, 1996).

Portanto, entendemos que a forma de análise que adotamos neste trabalho pode servir para nos fazer refletir a respeito destas aparentes contradições a partir de uma perspectiva diferente daquela que estamos habituados a realizar, já que, partindo desse pressuposto, a fala clara, lógica e objetiva se torna uma ilusão.

\section{2) Uso combinado de repertórios}

Mostraremos, a seguir, a relação e coexistência de mais de um repertório em um mesmo trecho de fala dos entrevistados, bem como a função dos repertórios dentro de cada contexto de conversa.

A) "Em busca da prevenção e autocuidado" e "A virtude da resignação"

Podemos observar aqui o uso do repertório da "busca da prevenção e autocuidado" (trecho sublinhado) seguido do uso do repertório da "virtude da resignação" (trechos em negrito). No trecho abaixo, D. Zilá refere-se ao uso da prótese como uma forma de cuidar de si, da sua saúde. Em seguida, faz uma reflexão a respeito de suas condições de saúde atuais e conclui essa reflexão utilizando o repertório da virtude da resignação, dizendo que "se Deus permitiu isso, vamos em frente."

L: A sra. acha, D. Zilá, que se não fossem as filhas da sra terem dado esse apoio e terem incentivado a sra, a sra acha que por conta própria a sra iria procurar (um centro auditivo)?

\section{Z: Ah, eu iria, mesmo assim eu iria. É a mesma coisa}

se você tivesse doente e tornar a procurar um médico, não é mesmo? Eu, como tenho muita saúde, eu analisei assim: "Gente, eu tenho tanta saúde, nunca fiz uma cirurgia”. A não ser última filha que foi preciso ser cesárea, né? Que eu já tava com as trompas inflamadas, já tinha cinco filhos, com ela seis, então, mas, sou muito sadia mesmo, né? Então, Deus permitiu isso, não, vamos em frente, não é mesmo? Se é pra ir, já que a gente tá usando óculos, né? Então deve ser mais ou menos isso, né? Só não faltar depois outras coisas, a visão, tá bom, né? (Zilá)

Neste caso, o repertório da "virtude da resignação" é usado com a função incentivadora/ motivacional de forma a complementar e a fortalecer o uso da prótese como "prevenção e autocuidado." Observamos isso no momento em que a entrevistada argumenta que "já que tem tanta saúde, nunca fez uma cirurgia", é como se fosse injusto se queixar sobre o fato de ter que usar a prótese auditiva. No final do trecho percebemos que a entrevistada ainda realiza um tipo de "barganha" com Deus, já que ela concorda em usar a prótese para cuidar de si ("já que Deus permitiu isso, vamos em frente, não é mesmo?"), mas espera que ele não permita que "falte depois outras coisas, a visão". Assim, podemos identificar ainda a função condicional do repertório da virtude da resignação para o uso da prótese auditiva, ou seja, a prótese é usada sem maiores problemas desde que Deus não permita a falta dos outros sentidos.

B) "O incômodo da repetição" e "Aproveitando um recurso tecnológico benéfico"

No trecho abaixo, podemos notar que, ao ser perguntado sobre o porquê da decisão de usar aparelho auditivo, o sr. Samuel responde utilizando, primeiramente, o repertório do "incômodo da repetição" (trecho sublinhado) e finaliza a explicação utilizando o repertório da prótese como "um recurso tecnológico benéfico" (trecho em negrito).

\section{L: E por que que o sr decidiu usar o aparelho, seu Samuel?}

\section{S: Uai, porque eu cansei da pessoa falar e cê tá pedindo pra repetir, outrora não entendia direito. Quando a gente não perguntava cê ficava naquela dúvida, eu achei que se tem o recurso, então vamos usá-lo, né? Então foi daí que eu resolvi a usar. (Samuel)}

Neste caso, é como se um repertório se apresentasse como a alternativa de resolução do outro, ou seja, a solução para o problema do incômodo da repetição é o uso do recurso tecnológico benéfico, neste caso, a prótese auditiva.

Podemos observar, assim, que os repertórios podem ter diferentes funções dependendo de quem usa e do contexto no qual é utilizado. 
Apesar de nossa classificação se basear em certas tendências e incidências de uso, podemos perceber que o uso dos repertórios não acontece de forma rígida ou imutável, ao contrário disso, os repertórios são flexíveis, podendo ser usados de forma isolada ou combinada. Não há uma regra fixa de uso, já que o sentido é mutável e se adapta às necessidades comunicativas e interativas de cada momento. Por meio desta análise, pudemos mostrar também que a decisão de usar a prótese auditiva não está referida a uma atitude constante, um traço de personalidade estável ou atividade cognitiva do indivíduo isolado, mas a um processo conversacional.

\section{Considerações Finais}

Através desta pesquisa, fomos capazes de identificar cinco repertórios interpretativos produzidos por idosos deficientes auditivos para justificar sua decisão de usar a prótese auditiva. A análise dos repertórios nos permitiu identificar também algumas funções de seu uso, bem como as implicações morais associadas a ele e as possíveis fragilidades decorrentes do uso isolado de cada um dos repertórios, o que leva os entrevistados a usá-los de maneira combinada.

Assim, pudemos perceber que, ao utilizar tais repertórios, os entrevistados procuram legitimar sua decisão de usar a prótese auditiva, mostrando que a mesma foi tomada de maneira criteriosa, levando em conta diversos aspectos e que, portanto, deve ser respeitada. Além disso, ao usar esses repertórios, os entrevistados buscam se aproximar de imagens moralmente positivas, posicionando-se como pessoas coerentes, flexíveis, conscientes, cuidadosas, inovadoras e sábias. Da mesma forma, também tentam garantir $\mathrm{o}$ afastamento de imagens negativas, como as de pessoas difíceis, inflexíveis e desinformadas. Assim, foi possível observar como os indivíduos se utilizam dos repertórios interpretativos para dar sustentação aos posicionamentos assumidos nas entrevistas, buscando sempre preservar a legitimidade de suas qualidades morais.

Além de identificar os repertórios interpretativos, este estudo nos possibilitou observar ainda o caráter contextual e situacional do uso dos mesmos, já que são usados de maneira combinada pelos entrevistados buscando sempre o fortalecimento e a legitimação dos seus argumentos em cada momento específico da entrevista.

Como já dito anteriormente, estudar este assunto a partir das contribuições do Construcionismo Social representou um grande desafio, já que a maioria das pesquisas realizadas sobre esta temática é tradicionalmente quantitativa, orientada por uma perspectiva realista. Por esse motivo, durante a construção do trabalho, apesar de termos incluído tais estudos em nossas parcerias conversacionais, buscamos entendê-los como sentidos privilegiados pela comunidade científica que também produzem uma versão sobre os idosos e o uso de próteses auditivas. Por meio desta pesquisa, buscamos, de forma complementar, apontar outros sentidos preferidos pelos idosos.

Vimos que os sentidos são produzidos durante as inter-relações humanas (Spink, 2004). Assim, a maneira como nos relacionamos com os nossos pacientes irá interferir na forma como eles irão dar sentido ao uso das próteses auditivas. Então, como já proposto por Russo (2004), devemos ter como compromisso ouvir o indivíduo de forma cuidadosa, buscando, durante nossas interações, manter uma postura dialógica que possa auxiliar o idoso no processo de reabilitação audiológica.

De forma geral, este estudo busca destacar a importância de os profissionais possuírem uma sensibilidade aos repertórios interpretativos disponíveis socialmente, os quais constroem, ampliando ou limitando, as possibilidades de sentido referentes às decisões em saúde. Estas possibilidades influem na relação que estabelecemos com nossos pacientes, delimitando também nossas ações de acolhimento, diálogo e negociação.

Pensamos ainda que futuros estudos, nos quais fossem entrevistados indivíduos idosos portadores de deficiência auditiva que optaram por não usar próteses auditivas, poderiam servir como contraponto para a reflexão a respeito do processo de produção de sentidos sobre os temas estudados nesta pesquisa.

\section{Referências}

Almeida, K. (2004). Seleção e adaptação de próteses auditivas em adultos. In L. P. Ferreira, D. M. Befi-Lopes, \& S. C. O Limongi (Orgs.), Tratado defonoaudiologia (pp. 669-679). São Paulo: Roca.

Assayag, F. H. M. \& Russo, I. C. P. (2006). Avaliação subjetiva do benéfico e dos efeitos proporcionados pelo uso de amplificação sonora em indivíduos idosos. Distúrbios da Comunicação, 18(3), 383-390.

Bacelar, R. (2002). Envelhecimento e produtividade: processos de subjetivação.

Recife: FASA.

Buzzo, B. C., Ubrig, M. T., \& Novaes, B. C. (2004). Aparelho de amplificação sonora individual: relações entre a autopercepção do handicap auditivo e as avaliações da percepção de fala. Distúrbios da Comunicação, 16(1), 17-25.

Costa, K. C. F. (2006). O sentido da deficiência auditiva e do uso de aparelhos de amplificação sonora para idosos. Dissertação de Mestrado, Pontifícia Universidade Católica de São Paulo, São Paulo.

Erler, S. F. \& Garstecki, D. C. (2002). Hearing loss and hearing aid related stigma: perceptions of women with age normal hering. American Journal of Audiology, 11, 83-91.

Fialho, I. M. (2001). Perda auditiva em idosos na percepção dos sujeitos.

Dissertação de Mestrado, Departamento de Saúde Pública, Universidade de São

Paulo, São Paulo.

Freire, S.A. (2000). Envelhecimento bem sucedido e bem-estar psicológico. In A. L. Neri \& S. A. Freire (Orgs.), E por falar em boa velhice (pp. 21-31). Campinas, SP: Papirus. 
Gates, G. A. \& Mills, J. H. (2005). Presbyacusis. The Lancet, 366(24), $1111-1120$

Gergen, K. J. (1985). The social constructionist movement in modern psychology. American Psychologist, 40, 266-275.

Gergen, K. J. (1997). Realities and relationships. Cambridge: Harvard University Press.

Giacomin, K. C., Uchoa, E., \& Lima-Costa, M. F. F. (2005). Projeto Bambuí: a experiência do cuidado domiciliário por esposas de idosos dependentes. Cadernos de Saúde Pública, 2(15), 1509-1518.

Hull, R. H. (1999). Atendimento ao Paciente Idoso. In J. Katz (Org.), Tratado de audiologia clínica (pp.783-792). São Paulo: Manole.

Iervolino, S. M. S., Castiglioni, M., \& Almeida, K. (2003). Aorientação e o aconselhamento no processo de reabilitação auditiva. In K. Almeida \& M. C. M. Iorio (Orgs.), Próteses auditivas: fundamentos \& aplicações clínicas (pp. 411-427). São Paulo: Lovise.

Instituto Brasileiro de Geografia e Estatística. (2002). Perfil dos idosos responsáveis pelos domicílios no Brasil - 2000. Rio de Janeiro: IBGE.

Instituto Brasileiro de Geografia e Estatística. (2007). Pesquisa Nacional por Amostra de Domicílios: síntese de indicadores 2006. Rio de Janeiro: IBGE. Acesso em 25 de abril, 2008, em http:// www.ibge.gov.br/home/estatistica/populacao/trabalhoerendimento/ pnad2006/sintesepnad2006.pdf

Kochkin, S. (2003). Marke Trake VI: On the issue of value: hearing aid benefit, price, satisfaction and brand repurchase rates. Hearing Review, 10(2), 12-26.

Papaléo Netto, M. \& Ponte, J. R. da. (1997). Envelhecimento: desafio na transição do século. In M. Papaléo Netto (Org.), Gerontologia (pp. 3-12). São Paulo: Atheneu.

Potter, J. (1996). Discourse analysis and constructionist approaches: Theoretical background. In J. T. E. Richardson (Org.), Handbook of qualitative researchmethods forpsychology and the social sciences (pp. 125-140). Leicester: BPS Books.

Potter, J. \& Wetherell, M. (1995). Discourse analysis. In J. A. Smith, R. Harré, \& L. V Langenhove (Orgs.), Rethinking methods in psychlogy (pp. 80-92). Londres: Sage.

Potter, J. \& Wetherell, M. (1996). From representations to repertoires. In J. Potter \& M. Wetherell (Orgs.), Discourse and social psychology: Beyond attitudes and behavior (pp. 138-157). Londres: Sage.

Rasera, E. F. \& Japur, M. (2001). Contribuições do pensamento construcionista para o estudo da prática grupal. Psicologia, Reflexão e Crítica, 14, 201-209.

Rasera, E. F. \& Japur, M. (2007). Grupo como construção social: aproximações entre o

construcionismo social e a terapia de grupo. São Paulo: Vetor.

Rigo, M. de L. N. R. \& Teixeira, D. de C. I. (2005). Efeitos da atividade física na percepção de bem estar de idosas que residem sozinhas e acompanhadas. UNOPAR Ciência, Biologia e Saúde, 7(1), 13-20.

Russo, I. C. P. (2004). Distúrbios da audição: a presbiacusia. In I. P. Russo (Org.), Intervenção fonoaudiológica na terceira idade (pp. 51-82). Rio de Janeiro: Revinter.

Russo, I. C. P., Almeida, K., \& Freire, K. M. (2003). Seleção e adaptação de prótese auditiva para o idoso. In K. Almeida \& M. C. M. Iorio (Orgs.), Próteses auditivas: fundamentos \& aplicações clínicas (pp. 385-407). São Paulo: Lovise.

Silman, S., Iório, M. C. M., Mizhahi, M. M., \& Parra, V. M. (2004). Próteses auditivas: um estudo sobre seu benefício na qualidade de vida de indivíduos portadores de perda auditiva neurossensorial. Distúrbios da Comunicação, 16(2), 153-165.

Spink, M. J. P. (2004). Práticas discursivas e produção de sentidos no cotidiano: aproximações teóricas e metodológicas. São Paulo: Cortez.
Spink, M. J. \& Medrado, B. (2004). Produção de sentidos no cotidiano: uma abordagem teórico-metodológica para análise das práticas discursivas. In M. J. Spink (Org.), Práticas discursivas e produção de sentidos no cotidiano: aproximações teóricas e metodológicas (pp. 41-61). São Paulo: Cortez.

Tesch-Römer, C. (1997). Psychological effects of hearing aid use in older adults. Journal of Gerontology: Psychological Sciences, 52b(3), 127-138.

Veras, R. P. \& Mattos, L. C. (2007). Audiologia do envelhecimento: revisão da literatura e perspectivas atuais. Revista Brasileira de Otorrinolaringologia, 73(1), 128-134.

Weinstein, B. E. \& Ventry, I. M. (1982). Hearing impairment and social isolation in the elderly. Journal of Speech and Hearing Research, 25, 593-599.

Luciana M. Ribeiro é Fonoaudióloga graduada pela Universidade de São Paulo e Mestre em Psicologia pela

Universidade Federal de Uberlândia. Endereço para correspondência: Rua Augusto Severo, 901/404.

Curitiba, PR, Brasil. CEP:80030-240

Email: fonolu@yahoo.com.br

Emerson F. Rasera é Doutor em Psicologia pela Universidade de São Paulo e Professor da Universidade Federal de Uberlândia. Endereço para correspondência:

Rua Goiás, 467/804. Uberlândia/MG. CEP:38400-064 Email: emersonrasera@uol.com.br

Os idosos e o uso de próteses auditivas: identificando os repertórios interpretativos que justificam essa decisão

Luciana M. Ribeiro e Emerson F. Rasera

Recebido: 30/01/2008

$1^{\text {a }}$ Revisão: $13 / 05 / 2008$

Aceite final: 12/07/2008 